\title{
Leishmania infantum DNA Detection in Urine from Patients with Visceral Leishmaniasis and after Treatment Control
}

\author{
Roser Fisa,* Cristina Riera, Paulo López-Chejade, Israel Molina, Montserrat Gállego, Vicenç Falcó, Esteban Ribera, \\ and Montserrat Portús \\ Laboratory of Parasitology, Universitat de Barcelona, Barcelona, Spain; Infectious Diseases Department, \\ Hospital Universitari Vall d'Hebron, Universitat Autònoma de Barcelona, Barcelona, Spain
}

\begin{abstract}
A urine-polymerase chain reaction (PCR) assay was validated for diagnosis of human visceral leishmaniosis (VL), taking advantage of the accessibility of urine samples. Leishmania infantum DNA presence was examined in 17 urine samples from 17 patients with VL during a clinical episode and in 55 urine samples from 17 patients with VL monitored after treatment at different intervals. Fifty-nine urine samples from 59 controls with no history of VL were also studied. The urine-PCR test was positive in 15/17 samples obtained during the episode (sensitivity, $88 \%$ ). None of the controls tested were urine-PCR positive (specificity, 100\%). During the monitoring period, $25 \%$ of the samples gave a positive urine-PCR. Results were compared with other diagnostic methods, such as urine antigen detection and peripheral blood-PCR and culture, with good concordance during the clinical episode and differences in the follow-up period. This study suggests that urine-PCR is sensitive for diagnosis and may be useful to monitor treatment efficacy.
\end{abstract}

\section{INTRODUCTION}

Visceral leishmaniosis (VL) is caused by Leishmania infantum in southern Europe, where it is often associated with human immunodeficiency virus (HIV). ${ }^{1}$ In this geographic area, it is estimated that $1.5-9 \%$ of patients with acquired immunodeficiency syndrome (AIDS) will develop leishmaniosis. ${ }^{2}$ HIV-Leishmania co-infected patients present a high percentage of relapses after treatment, ${ }^{2}$ which highlights the need to use non-invasive samples for diagnosis and monitoring. Because VL is a fatal disease unless it is treated, a rapid and accurate diagnosis is important.

Serologic tests have a high diagnostic value in immunocompetent patients, but their value is limited in HIV-infected patients, whose humoral immune response may be weak or non-existent. Also, serologic tests have a low value in the evaluation of the treatment because they remain positive for a period of some months to some years after clinical cure. ${ }^{1,2}$ Microscopic examination and culture of bone marrow, lymph node, and spleen aspiration are the conventional diagnostic procedures. Molecular methods based on polymerase chain reaction (PCR) have been described as good alternatives that increase sensitivity, allowing the use of non-invasive samples such as peripheral blood. ${ }^{3-5}$ Other body fluids like urine and nasal and tonsillopharyngeal secretions have been cited as samples where amastigotes could be present. ${ }^{6}$ Detection of viable amastigotes by successful culture in the urine of patients with $\mathrm{VL}^{6}$ and the visualization of amastigotes or DNA detection of the parasite in urine from infected dogs ${ }^{7,8}$ have been reported. Additionally, the presence of Leishmaniaderived antigens in human urine has been cited repeatedly. ${ }^{9-12}$ This study sought to evaluate the usefulness of urine in a PCR-based test for diagnosis and monitoring of VL.

\section{MATERIALS AND METHODS}

Subjects and samples. One hundred thirty-one urine samples from 87 individuals were included in the study. Sev-

* Address correspondence to Roser Fisa, Laboratory of Parasitology, Faculty of Medicine, Avda Joan XXIII sn, Barcelona, Spain 08028. E-mail: rfisa@ub.edu enty-two of the urine samples were from 28 adult patients with VL, 24 of whom were Leishmania-HIV co-infected, and had attended the Hospital Vall d'Hebron (Barcelona, Spain). Seventeen samples were obtained from 17 patients (16 HIV+) during a VL clinical episode, and 55 samples were obtained from 17 patients (13 HIV+, 48 samples) during the asymptomatic monitoring period after treatment that lasted from 1 month to 3 years. Patients were treated with pentavalent antimonials or lipid formulation of amphotericin B, and immunocompromised patients were maintained with chemoprophylaxis. Fifty-nine urine samples from 59 adult controls (16 $\mathrm{HIV}+$ patients and 43 healthy people), all of them from endemic areas of leishmaniosis and without a history of VL, were also studied.

Blood samples were obtained simultaneously with the urine sample from patients with VL and from the control group of HIV+ patients without a VL history. The VL episode was diagnosed on the basis of clinical symptoms and confirmed by detection of Leishmania in bone marrow aspirates by microscopic examination and/or culture. All patients gave their signed, informed consent for participation in this study.

Collection of samples and methods. Samples of urine were collected and stored under refrigeration $\left(4^{\circ} \mathrm{C}\right)$ within 2 days of collection or frozen to $-40^{\circ} \mathrm{C}$ until use and thawed at room temperature for PCR analysis and antigen detection. Urine $(10 \mathrm{~mL})$ was centrifuged at $15,000 \mathrm{~g}$ in sterile tubes for 10 minutes, the supernatant was discarded, the pellet was washed twice in sterile phosphate-buffered saline (PBS) and centrifuged again, and the final pellet was resuspended in 0.5 $\mathrm{mL}$ of PBS. DNA was extracted from $0.2 \mathrm{~mL}$ of sediment with the High Pure PCR Template kit (Roche Molecular Biochemicals, Mannheim, Germany) and frozen at $-20^{\circ} \mathrm{C}$ until PCR was performed. One milliliter of refrigerated urine was tested for Leishmania antigen detection by KAtex (ADU), following the instructions of the manufacturer (Kalon Biologic, Aldershot, UK).

Samples of blood were collected into EDTA tubes for PCR analysis and culture. Peripheral blood mononuclear cells (PBMCs) were isolated from $9 \mathrm{~mL}$ of peripheral blood by the Ficoll-Paque Plus procedure (Amersham Biosciences, Little Chalfont, UK). The PBMC pellet was washed twice in sterile PBS and resuspended in $0.6 \mathrm{~mL}$ of sterile PBS; $0.2 \mathrm{~mL}$ of 
PBMC suspension was used for DNA extraction with the High Pure PCR Template kit for PCR analysis, and the remaining $0.4 \mathrm{~mL}$ was inoculated into NNN medium and Schneider media for in vitro cultivation. ${ }^{13}$ Cultures were maintained at $24-26^{\circ} \mathrm{C}$, examined twice a week, and sub-cultured before being considered negative after a minimum of 3 months.

DNA amplification. DNA extracts were subjected to amplification of a genetic region with specific L. infantum oligonucleotide primers in a nested PCR, with the pair of primers Ext-E2b and P1-P2 previously described. ${ }^{5}$ The PCRs were carried out in duplicate in a total volume of $20 \mu \mathrm{L}$ with $1 \times$ PCR buffer (10 mmol/L Tris-HCl, $\mathrm{pH} 8.3,50 \mathrm{mmol} / \mathrm{L} \mathrm{KCl}, 1.5$ $\mathrm{mmol} / \mathrm{L} \mathrm{MgCl}_{2}$, and $0.01 \%$ gelatin), $1.5 \mathrm{mmol} / \mathrm{L} \mathrm{MgCl}_{2}, 100$ $\mu \mathrm{mol} / \mathrm{L}$ of each deoxynucleotide triphosphate, $0.2 \mu \mathrm{mol} / \mathrm{L}$ of each primer, and 1 unit of RedTaq polymerase (Sigma, St. Louis, MO). Three microliters of DNA extract was used for the first PCR, which amplifies a 145-bp amplicon, and $2 \mu \mathrm{L}$ of the amplified product was used for the second. The PCR program was run on an $\mathrm{MJ}$ Research thermocycler at $96^{\circ} \mathrm{C}$ for 5 minutes, 30 cycles of $94^{\circ} \mathrm{C}$ for 30 seconds, $59^{\circ} \mathrm{C}$ for $30 \mathrm{sec}$ onds, and $72^{\circ} \mathrm{C}$ for 30 seconds, followed by 5 minutes at $72^{\circ} \mathrm{C}$ for both amplifications. To avoid cross-contamination and sample carryover, pre- and post-PCR sample processing and PCR amplification were performed in separate rooms, and plugged pipette tips were used for all fluid transfers. The amplification profile consisted of 100-bp product, which was visualized on a $3 \%$ agarose gel by ultraviolet transillumination after staining with ethidium bromide.

Statistical analysis. Between-test agreement was determined by the concordance coefficient, measured by the Cohen $\kappa$ statistic $(\kappa>0.75$ substantial agreement; $\kappa=0.4-0.75$, fair to good agreement; $\kappa<0.40$, poor agreement). ${ }^{14,15}$

\section{RESULTS}

Detection of $L$. infantum DNA in the 17 urine samples tested from patients with VL (16 HIV+ and $1 \mathrm{HIV}-)$ during the clinical episode yielded 15 positive results. Negative urine-PCR results obtained corresponded to two HIV+ patients, one patient with demonstrable presence of Leishmania in blood by PCR and culture and a positive ADU, and the other with negative blood-PCR and culture and a positive ADU. No false-positive results were observed among the 16 control HIV+ patients without a history of VL and the 43 healthy controls (Table 1). Results of urine-PCR during the VL clinical episode were similar in terms of sensitivity to those yielded by PCR in blood samples, blood culture, and ADU (Tables 1 and 2), with a positive predictive value of $100 \%$.

Urine-PCR detected Leishmania DNA in 14 of the 55 urine samples obtained, at different times, during the asymp-
TABLE 2

Contingency table of results obtained with urine-PCR versus ADU, blood-PCR, and blood culture in samples from 17 patients with VL obtained during the clinical episode

\begin{tabular}{|c|c|c|c|c|c|c|c|}
\hline & & & & & & & \\
\hline & & + & - & + & - & + & - \\
\hline & + & 13 & 2 & 15 & 0 & 14 & 1 \\
\hline Urine-PCR & - & 2 & 0 & 1 & 1 & 1 & 1 \\
\hline
\end{tabular}

tomatic post-treatment control period (Tables 1 and 3 ). Those positive samples corresponded to six Leishmania-HIV coinfected patients with intermittent positive results in urinePCR (14/31 urine samples), as well as in other analytical techniques carried out (ADU, 20/31; blood-PCR, 23/31; blood culture, 12/31). Evidence of a clinical episode, after the controlled asymptomatic period, was observed in three such patients. Another patient who also relapsed had repeated negative urine-PCR results, despite having positive ADUs and intermittent positive blood-PCRs and cultures.

During the post-treatment period, urine-PCR yielded lower sensitivity than ADU and blood-PCR (McNemar test, $P<0.05)$, and the agreement between techniques was poor. The coefficient of concordance between urine-PCR and ADU was $\kappa=0.30$ (95\% confidence interval, $0-0.58)$ and with blood-PCR was $\kappa=0.22$ (95\% confidence interval, $0-0.56)$. Leishmania DNA detection in urine yielded a similar sensitivity to that of blood culture (McNemar test, $P>0.05$ ), with a coefficient of concordance between techniques of $\kappa=$ 0.52 (95\% confidence interval, 0.26-0.78; Table 3).

\section{DISCUSSION}

The application of PCR techniques for diagnosis of VL has meant an improvement in the diagnosis and post-treatment control of this disease, because it obviates the need to use invasive samples such as bone marrow, lymph node, or spleen aspirates. Blood-PCR has been extensively used for VL diagnosis, with a range of sensitivities of $55-100 \% ., 16,17$

In this work, we studied the presence of Leishmania DNA in the urine of patients with VL for diagnosis purposes. We used a PCR technique based on the amplification of an $L$. infantum genomic DNA sequence of $100 \mathrm{bp}$ previously proven effective for VL diagnosis in blood $^{5}$ and other biologic samples. ${ }^{18}$ Urine-PCR has proven to be a sensitive technique for diagnosis of VL during the acute phase of disease, similar to ADU, blood-PCR, and blood culture, mainly in HIV+ patients, who are the principal patient population in South Europe. ${ }^{1}$ Antigen and DNA detection in urine was discordant in four cases, despite their showing the same sensitivity, and

TABLE 1

Urine-PCR results from 131 urine samples from patients with VL and controls

\begin{tabular}{|c|c|c|c|c|}
\hline \multirow[b]{2}{*}{ Group } & \multicolumn{2}{|c|}{ Urine } & \multicolumn{2}{|c|}{ Blood } \\
\hline & PCR & ADU & PCR & Culture \\
\hline VL clinical episode & 15/17 (88\%) & 15/17 (88\%) & 16/17 (94\%) & 15/17 (88\%) \\
\hline VL post-treatment & $14 / 55(25 \%)$ & $24 / 55(44 \%)$ & $37 / 55(67 \%)$ & $14 / 55(25 \%)$ \\
\hline HIV+ controls & $0 / 16(0 \%)$ & $0 / 16(0 \%)$ & $0 / 16(0 \%)$ & $0 / 16(0 \%)$ \\
\hline Healthy controls & $0 / 43(0 \%)$ & $0 / 43(0 \%)$ & ND & ND \\
\hline
\end{tabular}

Comparison with results from ADU, blood-PCR, and blood culture.

$\mathrm{ND}$, not done. 
TABLE 3

Contingency table of results obtained with urine-PCR versus ADU, blood-PCR, and blood culture from the patients with VL obtained during the monitoring period after treatment

\begin{tabular}{rrrrrrrr}
\hline & & \multicolumn{7}{c}{ Monitoring period } \\
\cline { 3 - 8 } & & \multicolumn{3}{c}{ ADU } & \multicolumn{2}{c}{ Blood-PCR } & \multicolumn{2}{c}{ Blood culture } \\
\cline { 3 - 8 } & & + & - & + & - & + & - \\
\hline \multirow{3}{*}{ Urine-PCR } & + & 10 & 4 & 13 & 1 & 9 & 5 \\
\hline
\end{tabular}

both tests were complementary, because all VL episodes could be diagnosed when urine was used as a sample, using either procedure, which reflects their different target nature. DNA in urine was, in all cases, accompanied by DNA in blood.

The presence of Leishmania DNA in urine may be the consequence of the passage of DNA through the glomerular barrier caused by renal lesions, common in VL, and the parasite's presence in the urinary tract. ${ }^{19-21}$ Tubulointerstitial involvement and glomerulonephritis are the main causes of the proteinuria that is present in most patients with a clinical episode of leishmaniosis, and the presence of Leishmaniaspecific $\operatorname{IgG}$ in the urine of dogs with leishmaniosis has also been attributed to an impairment of filtration of the glomerular barrier and, to a lesser extent, the local antibody production in the urinary tract. ${ }^{22}$ Fragments of postapoptotic DNA of 150-200 bp from cells dying throughout the body may cross the kidney barrier and appear in urine in the form of transrenal DNA. ${ }^{23,24}$ It is thus to be expected that fragments of Leishmania DNA containing the 100-bp sequence that was amplified by nested PCR were present in urine when the parasite was present in blood. The scarce false-negative urine-PCR results obtained in our patients during their VL clinical episode could be explained by a low parasite rate in blood; this was presumably the reason in one patient in which blood-PCR and culture were also negative. Other reasons may be the incapacity of the Leishmania DNA to cross the kidney barrier and appear in urine or technical problems during urine collection, preservation, DNA extraction, or amplification, which was impossible to confirm.

The low parasitic loads present in asymptomatic patients during post-treatment and a secondary chemoprophylaxis control period entails a decrease of positive results when using different diagnostic techniques. High sensitive techniques such as blood-PCR yield more positive results than culture when parasitemia is low. ${ }^{5,13,25}$ In our patients, this was reflected in a low agreement between tests, and DNA detection in urine was less sensitive than ADU and DNA detection in blood after treatment.

Studies performed on patients with VL during their posttreatment control period, ${ }^{5,13}$ and cryptic leishmaniosis in blood donors from endemic areas, ${ }^{26,27}$ reported a low number of blood culture positives as a consequence of the low number of parasites in blood, because cultures initiated with low inoculums fail to promote cell growth. ${ }^{28}$ This was consistent with our results on DNA detection in urine as urine-PCR and blood culture, in samples obtained during the asymptomatic after treatment period had similar sensitivity, and both techniques yield the highest agreement coefficient $(\kappa=0.49 ; 95 \%$ confidence interval, 0.23-0.75).

Our results indicate that Leishmania DNA is present in urine during the active phases of the disease or when a high parasitic load is present and its tendency to clearance after treatment when parasitic loads decrease and renal function improves. Studies on Leishmania-HIV co-infected patients during the post-treatment control period showed that a positive ADU or blood-PCR is not associated with a risk of clinical relapse that is otherwise related with a positive blood culture. ${ }^{13}$ Nevertheless, further studies are needed to better characterize the use of urine PCR in the diagnosis of VL in HIV - patients as well as in the post-treatment follow-up in both HIV+ and HIV- patients with VL and to relate results with the disease evolution and prognosis. The feasibility to work with two easy-to-obtain samples, such as blood and urine, reduces the need for traumatic bone marrow and risky spleen aspiration sampling for the diagnosis and posttreatment control of VL.

Received July 19, 2007. Accepted for publication November 20, 2007.

Acknowledgments: The authors thank S. Tebar for excellent technical assistance and R. Rycroft for English revision of the manuscript.

Financial support: This study was partially supported by Grant ACES 2006 Universitat of Barcelona.

Authors' addresses: Roser Fisa, Cristina Riera, Paulo LópezChejade, Montserrat Gállego, and Montserrat Portús, Laboratory of Parasitology, Faculty of Pharmacy, Universitat de Barcelona, Avda Joan XXIII s/n, 08028, Barcelona, Spain, Telephone: 34-93-4024502, Fax: 34-93-4024504. Israel Molina, Vicenç Falcó, and Esteban Ribera, Infectious Diseases Department, Hospital Universitari Vall d'Hebron, Universitat Autònoma de Barcelona, Paseig Vall d'Hebron 119-129, 08035 Barcelona, Spain, Telephone: 34-93-2746090.

\section{REFERENCES}

1. Desjeux P, Alvar J, 2003. Leishmania/HIV co-infections: epidemiology in Europe. Ann Trop Med Parasitol 97: 3-15.

2. Alvar J, Cañavate C, Gutierrez-Solar B, Jiménez M, Laguna F, López-Vélez R, Molina R, Moreno J, 1997. Leishmania and human immunodeficiency virus coinfection: the first 10 years. Clin Microbiol Rev 10: 298-319.

3. Smyth AJ, Ghosh A, Hassan MQ, Basu D, De Bruijn MH, Adhya S, Mallik KK, Barker DC, 1992. Rapid and sensitive detection of Leishmania kinetoplast DNA from spleen and blood samples of kala-azar patients. Parasitology 105: 183-192.

4. Pizzuto M, Piazza M, Senese D, Scalamogna C, Calattini S, Corsico L, Persico T, Adriani B, Magni C, Guaraldi G, Gaiera G, Ludovisi A, Gramiccia M, Galli M, Moroni M, Corbellino M, Antinori S, 2001. Role of PCR in diagnosis and prognosis of visceral leishmaniasis in patients coinfected with human immunodeficiency virus type 1. J Clin Microbiol 39: 357-361.

5. Fisa R, Riera C, Ribera E, Gállego M, Portús M, 2002. A nested polymerase chain reaction for diagnosis and follow-up of human visceral leishmaniasis patients using blood samples. Trans $R$ Soc Trop Med Hyg 96: S191-S194.

6. Mebrahtu YB, Hendricks LD, Oster CN, Lawyer PG, Perkins PV, Pamba H, Koech D, Roberts CR, 1993. Leishmania donovani parasites in the nasal secretions, tonsillopharyngeal mucosa, and urine centrifugates of visceral leishmaniasis patients in Kenya. Am J Trop Med Hyg 48: 530-535.

7. Riera C, Valladares JE, 1996. Viable Leishmania infantum in urine and semen in experimentally infected dogs. Parasitol Today 12: 412.

8. Solano-Gallego L, Rodriguez-Cortes A, Trotta M, Zampieron C, Razia L, Furlanello T, Caldin M, Roura X, Alberola J, 2007. Detection of Leishmania infantum DNA by fret-based realtime PCR in urine from dogs with natural clinical leishmaniosis. Vet Parasitol 147: 315-319.

9. De Colmenares M, Portús M, Riera C, Gállego M, Aisa MJ, Torras S, Muñoz C, 1995. Short report: detection of 72-75-kD 
and $123-\mathrm{kD}$ fractions of Leishmania antigen in urine of patients with visceral leishmaniasis. Am J Trop Med Hyg 52: 427-428.

10. Kohanteb J, Ardehali SM, Rezai HR, 1987. Detection of Leishmania donovani soluble antigen and antibody in the urine of visceral leishmaniasis patients. Trans $R$ Soc Trop Med Hyg 81: 578-580.

11. Attar ZJ, Chance ML, el-Safi S, Carney J, Azazy A, El-Hadi M, Dourado C, Hommel M, 2001. Latex agglutination test for the detection of urinary antigens in visceral leishmaniasis. Acta Trop 78: 11-16.

12. Riera C, Fisa R, López-Chejade P, Ribera E, Carrió J, Falcó V, Molina I, Gállego M, Portús M, 2004. Evaluation of a latex agglutination test (KAtex) for detection of Leishmania antigen in urine of patients with HIV-Leishmania coinfection: value in diagnosis and post-treatment follow-up. Eur J Clin Microbiol Infect Dis 23: 899-904.

13. Riera C, Fisa R, Ribera E, Carrió J, Falcó V, Gállego M, Moner L, Molina I, Portús M, 2005. Value of culture and nested polymerase chain reaction of blood in the prediction of relapses in patients co-infected with Leishmania and human immunodeficiency virus. Am J Trop Med Hyg 73: 1012-1015.

14. Giovannelli L, Lama A, Capra G, Giordano V, Arico P, Ammatuna $P, 2004$. Detection of human papillomavirus DNA in cervical samples: analysis of the new PGMY-PCR compared to the hybrid capture II and MY-PCR assays and a two-step nested PCR assay. J Clin Microbiol 42: 3861-3864.

15. Cohen J, 1960. A coefficient of agreement for nominal scales. Educ Psychol Meas 20: 37-46.

16. Lachaud L, Dereure J, Chabbert E, Reynes J, Mauboussin JM, Oziol E, Dedet JP, Bastien P, 2000. Optimized PCR using patient blood samples for diagnosis and follow-up of visceral leishmaniasis, with special reference to AIDS patients. J Clin Microbiol 38: 236-240.

17. Bossolasco S, Gaiera G, Olchini D, Gulletta M, Martello L, Bestetti A, Bossi L, Germagnoli L, Lazzarin A, Uberti-Foppa C, Cinque P, 2003. Real-time PCR assay for clinical management of human immunodeficiency virus-infected patients with visceral leishmaniasis. J Clin Microbiol 41: 5080-5084. Erratum in J Clin Microbiol 42: 1858.
18. Fisa R, Riera C, Gállego M, Manubens J, Portús M, 2001. Nested PCR for diagnosis of canine leishmaniosis in peripheral blood, lymph node and bone marrow aspirates. Vet Parasitol 99: 105111.

19. Caravaca F, Munoz A, Pizarro JL, Saez de Santamaria J, Fernandez-Alonso J, 1991. Acute renal failure in visceral leishmaniasis. Am J Nephrol 11: 350-352.

20. Dutra M, Martinelli R, de Carvalho EM, Rodrigues LE, Brito E, Rocha H, 1985. Renal involvement in visceral leishmaniasis. Am J Kidney Dis 6: 22-27.

21. Salgado Filho N, Ferreira TM, Costa JM, 2003. [Involvement of the renal function in patients with visceral leishmaniasis (kalaazar)]. Rev Soc Bras Med Trop 36: 217-221.

22. Solano-Gallego L, Rodriguez A, Iniesta L, Arboix M, Portús M, Alberola J, 2003. Detection of anti-Leishmania immunoglobulin $\mathrm{G}$ antibodies in urine specimens of dogs with leishmaniasis. Clin Diagn Lab Immunol 10: 849-855.

23. Lichtenstein AV, Melkonyan HS, Tomei LD, Umansky SR, 2006. Novel applications of polymerase chain reaction to urinary nucleic acid analysis. Methods Mol Bio 336: 145-154.

24. Umansky SR, Tomei LD, 2006. Transrenal DNA testing: progress and perspectives. Expert Rev Mol Diagn 6: 153-163.

25. Mary C, Faraut F, Lascombe L, Dumon H, 2004. Quantification of Leishmania infantum DNA by a real-time PCR assay with high sensitivity. J Clin Microbiol 42: 5249-5255.

26. Riera C, Fisa R, Udina M, Gállego M, Portús M, 2004. Detection of Leishmania infantum cryptic infection in asymptomatic blood donors living in an endemic area (Eivissa, Balearic Islands, Spain) by different diagnostic methods. Trans $R$ Soc Trop Med Hyg 98: 102-110.

27. Le Fichoux Y, Quaranta JF, Aufeuvre JP, Lelievre A, Marty P, Suffia I, Rousseau D, Kubar J, 1999. Ocurrence of Leishmania infantum parasitemia in asymptomatic blood donors living in an area of endemicity in Southern France. J Clin Microbiol 37: 1953-1957.

28. Lemesre L, Darcy F, Kweider M, Capron A, Santero F, 1988. Requirements of defined cultivation conditions for standard growth of Leishmania promastigotes in vitro. Acta Trop 45: 99-108. 